Universidad de Guadalajara

DERECHO GLOBAL. ESTUDIOS SOBRE DERECHO Y JUSTICIA

Año 2021, Vol. VI. Número 18, Julio-Octubre, ISSN: 2448-5128 e-ISSN: 2448-5136

https://DOI.org/10.32870/dgedj.v6i18.412

JOHN FERNANDO RESTREPO TAMAYO

Universidad de Medellín, Colombia

jfrestrepo@udem.edu.co

JUAN CAMILO GALLO GÓMEZ

Universidad de Medellín, Colombia

jgallo@udem.edu.co

\title{
RAZÓN PÚBLICA Y JUSTICIA DEMOCRÁTICA: LOS FUNDAMENTOS TEÓRICOS DE LA DEMOCRACIA CONSTITUCIONAL EN EL PENSAMIENTO POLÍTICO DE JOHN RAWLS ${ }^{1}$
}

\section{Public Reason and Democratic Justice: THE THEORETICAL BASIS OF CONSTITUTIONAL DEMOCRACY IN RAWLS' POLITICAL THEORY}

Cómo citar el artículo:

Restepro J y Gallo J, (2021). Razón Pública y Justicia Democrática: Los Fundamentos Teóricos de la Democracia Constitucional en el pensamiento político de John Rawls. Derecho Global, Estudios sobre Derecho y Justicia, VI (18) https://DOI.org/10.32870/dgedj.v6i18.412 pp. 171-197

Recibido: 06/10/2020 Aceptado: 27/03/2021

\footnotetext{
${ }^{1}$ La redacción de este artículo es resultado del trabajo académico que se adelanta en la Línea de Estado, Democracia y Constitución del Grupo de Investigación en Conflicto y Paz (Categoría A1/ Colciencias) de la Facultad de Ciencias Sociales y Humanas de la Universidad de Medellín.
} 


\title{
RESUMEN
}

El artículo expone los principios teóricos de la filosofía política de John Rawls para establecer el vínculo entre democracia constitucional y la teoría de la justicia. Para esto, se exploran primero los conceptos fundamentales de la teoría rawlsiana como principios de justicia, posición original, velo de ignorancia, consenso entrecruzado y razón pública. A partir de allí, se desarrolla una reflexión en torno al papel de la Constitución y del tribunal constitucional; para finalmente concluir que existe una base teórica de justificación de la democracia constitucional en el pensamiento de Rawls.

\section{Palabras clave}

Democracia, Justicia, Tribunal constitucional, Constitución, Razón pública, liberalismos políticos.

\begin{abstract}
The paper exposes the theoretical principles of John Rawls' political philosophy to establish the link between constitutional democracy and the theory of justice. For this, the fundamental concepts of Rawlsian theory such as principles of justice, original position, veil of ignorance, intersecting consensus and public reason are first explored. From there, a reflection is developed around the role of the constitution and the constitutional court; to finally conclude that there is a theoretical basis for the justification of constitutional democracy in Rawls' thought.
\end{abstract}

\section{KEYWORDS}

Democracy, Justice, Constitutional Court, Constitution, Public Reason, Political Liberalism.

Sumario: I. Introducción. II. Elementos teóricos de la teoría de la democracia liberal de John Rawls. III. El liberalismo político y la justificación iusfilosófica de la constitución. 1. Cómo la razón pública se relaciona y depende de la idea de ciudadanía democrática. 
Razón pública y justicia democrática: Los fundamientos teóricos de la democracia constitucional

2. Diferencias entre razones no públicas y públicas. 3. Contenido de la razón pública. 4. Esencias constitucionales y asuntos de justicia básica. IV. El orden jurídico a la luz de la razón pública. V. Conclusiones. Bibliografía.

Todos los valores sociales — libertad y oportunidad, ingreso y riqueza, así como las bases del respeto a sí mismo- habrán de ser distribuidos igualitariamente a menos que una distribución desigual de alguno o de todos estos valores redunde en una ventaja para todos. La injusticia consistirá entonces, simplemente, en las desigualdades que no benefician a todos.

John Rawls, Teoría de la justicia

\section{INTRODUCCIÓN}

John Rawls es uno de los pensadores que en el campo de la filosofía política y moral ha tenido mayor influencia en la segunda mitad del siglo XX (Alútiz, 2004, p. 5). Desde 1971 con su obra cumbre Teoría de la Justicia (2006), Rawls revivió los debates filosóficos en torno a la justicia política y social, que habían sido relegados a las discusiones entre juristas. Su intento por responder a las preguntas por las condiciones justas de cooperación en una sociedad bien ordenada y los parámetros para el consenso entre diferentes cosmovisiones propias de una democracia pluralista, marcó precedentes teóricos para la Filosofía, y han guiado gran parte de las discusiones académicas durante las últimas décadas del siglo XX y nuestros días. Van Parjis sintetiza la genialidad de la obra de John Rawls en una doble dirección: (i) el método de justificación con el que se aproxima a la filosofía política y, (ii) el contenido de los principios de justicia con los que justifica la construcción de una sociedad justa y ordenada (1994, pp. 7-33). Su magistral argumentación en torno a la idea de que la riqueza desigualmente distribuida se transforma en un factor de injusticia, no solo social, sino también política en la medida en que desigualdad económica se transforma en desigualdad política, se ha consolidado como uno de los mayores logros de la reflexión constitucional y filosófica en los últimos años (Pogge, 2010; Freeman, 2007; Mandle, 2009). 
John Rawls ha defendido su propuesta en diversos textos y publicaciones. Como intento de respuesta a sus críticos, Rawls editó una serie de conferencias en Liberalismo político (2003), en el cual reformula algunas de las ideas básicas planteadas en 1971 (Pogge, 2010). Pero aquí no se detuvo el interés de críticos y académicos por la obra del norteamericano y, por tal motivo, ya en sus últimos años de vida, Rawls reeditó algunas de sus ideas básicas en una publicación titulada Justicia como equidad: una reformulación (2002). Para el desarrollo de este artículo se tendrán en cuenta las tres versiones publicadas de su teoría dado que el pensador norteamericano siempre conservó la unidad metodológica y conceptual en su proyecto (Pogge, 2010; Floyd, 2017; Wenar, 2005).

La pretensión esencial de Rawls consiste en identificar las condiciones procedimentales que permitan a los sujetos políticos establecer reglas de cooperación social, a través de las cuales resulte posible convivir políticamente sin tener que renunciar a las concepciones particulares de bien que cada individuo posee y que en la mayoría de los casos pueden llegar a ser incompatibles con las de los demás. El proyecto filosóficopolítico rawlsiano se inscribe en el plano de una teoría democrática y pluralista por cuanto no aboga por la homogeneización de las ideas de los sujetos, sino que posee como base misma del proceso de deliberación, la proliferación de concepciones particulares del bien y la vida buena. Toda la teoría con la que se dé respuesta a esta búsqueda de la construcción de un nuevo contrato social (Rawls, 2006, p. 17; Freeman, 2007, p. 32), ha requerido establecer unos presupuestos esenciales que tienen que ver con la idea de personas, sus facultades morales y un tipo de sociedad bien organizada. La construcción de la teoría rawlsiana permite establecer, entonces, una serie de relaciones teóricas con la justificación de la democracia constitucional (Ferrajoli, 2008,37) y la razón pública como criterio general de consenso entrecruzado en una sociedad garantista de los derechos fundamentales (Ferrajoli, 2014, 56Ferrajoli, 2010, 37; Fraguas, 2015) y la diferencia.

En este artículo pretendemos establecer una defensa de la democracia constitucional con su sistema de garantías, controles políticos y prácticas sociales de legitimación a partir de las ideas de Rawls. En este contexto se debe

\section{DERECHO GLOBAL. ESTUDIOS SOBRE DERECHO Y JUSTICIA}


señalar que la Democracia constitucional establece la posibilidad de asegurar la participación y la representación política de todos los asociados a la luz de los principios constitucionales que visibilizan al poder judicial como garante de unas reglas de juego en la que los derechos fundamentales y la división de poderes juegan un papel decisivo. Esta tarea resulta relevante en tanto que hoy en día nos enfrentamos al surgimiento de corrientes políticas que han puesto en riesgo los logros pluralistas y la protección de derechos de las minorías y grupos en desventaja social en los entramados institucionales contemporáneos (Mounk, 2018; Levitsky y Ziblatt, 2018). Para llevar a cabo tal pretensión, este texto se compone de los siguientes apartados: (1) elementos esenciales de la teoría liberal de la democracia; (2) definición de liberalismo político y explicación de la idea de razón pública como introducción al derecho constitucional; (3) filosofía del derecho a partir de la teoría de Rawls y, (4) conclusiones.

\section{ELEMENTOS TEÓRICOS DE LA TEORÍA DE LA DEMOCRACIA LIBERAL DE JOHN RAWLS}

El problema fundamental de la obra rawlsiana gira en torno a la pregunta por los términos equitativos de cooperación social entre ciudadanos libres e iguales, a fin de que dicha sociedad sea bien ordenada y perdure a lo largo del tiempo. En este sentido, Rawls desarrolla una reflexión teórica que revivió las consideraciones filosóficas en el campo del análisis político que habían quedado reducidas a pretensiones puramente descriptivas desde las metodologías positivistas (Mandle, 2009, Freeman, 2007). Rawls lleva a un nivel más alto de abstracción las consideraciones contractualistas sobre el consenso como fundamento de legitimidad de las relaciones políticas (Rawls, 2003, p. 10; 2006, p.17).

El problema de la justicia, como pregunta recurrente en la obra de Rawls es la máxima expresión de su intención moral (Kukathas y Pettit, 1990). Esta premisa básica fue el objeto de trabajo de toda una vida académica que suma más de cuarenta 
años (Pogge, 2010). El punto central de la noción de justicia como problema filosófico consiste en explicar de qué manera pueden todos los asociados vivir en sociedad, según sus nociones propias de bien, en el interior de una sociedad justa y ordenada. Desde su perspectiva, es posible pensar una sociedad donde los asociados sean capaces de conservar sus concepciones de bien a la vez que coincidir en unos presupuestos básicos de inclusión donde la justicia resulte posible; y tanto las instituciones políticas como los asuntos públicos se ajusten a dichos presupuestos.

La noción de justicia de Rawls no es solo una abstracción moral. Lo justo exige que haya lugar a unas condiciones materiales de corrección al liberalismo clásico del Estado mínimo. La defensa de los bienes sociales primarios y la satisfacción de necesidades en favor de los menos aventajados es una clara muestra del perfil socialdemócrata que avisa la obra de este gran pensador.

La concepción política de justicia tiene tres rasgos característicos. En primer lugar, se dirige a la estructura básica de la sociedad, es decir, a las instituciones políticas, sociales y económicas que conforman el entramado social, y la manera en que éstas se relacionan entre sí (p.41). Rawls la define de la siguiente forma: "La estructura básica es el marco social de trasfondo en cuyo seno tienen lugar las actividades de las asociaciones y los individuos. Una estructura básica asegura lo que podemos llamar justicia de trasfondo" (2002, p. 33)². En segundo lugar, se presenta de un modo independiente. No es una concepción moral, general y comprehensiva en sí misma, permitiendo que todos los asociados conserven sus concepciones morales razonables y a su vez encuentren que esta concepción política de la justicia resulta compatible con sus creencias (Rawls, 2003, p. 42). Por último, la concepción política de la justicia se expresa en términos que describen valores propios de una cultura pública en una sociedad democrática ( $p$. 43).

\footnotetext{
${ }^{2}$ Como ejemplo de formas institucionales que hacen parte de la estructura básica, Rawls propone la idea de una Constitución política con judicatura independiente y las disposiciones sociales y económicas (que regulan el libre intercambio de bienes y beneficios). (Rawls, 2006, p. 20)
} 
La idea de sociedad como sistema equitativo de cooperación es aquella que tiene tres elementos básicos: (i) las relaciones de cooperación social están determinadas por reglas de juego públicas que todas las partes sociales pueden aceptar como justas e imparciales; (ii) cada asociado orienta su comportamiento de acuerdo con estas reglas y, (iii) la idea de cooperación incluye una ventaja racional a cada asociado (Freeman, 2007; Mandle, 2009). Para la regulación de la cooperación social a través de una concepción política de la justicia se necesita partir de la concepción de los ciudadanos como personas libres e iguales, es decir, como sujetos que participan en la cooperación social, plenamente capaces de hacerlo y a lo largo del tiempo. Estos ciudadanos deben concebirse a la luz de dos facultades morales: racionalidad y razonabilidad. La primera facultad moral hace referencia a la capacidad de poseer un sentido de la justicia y optar por ella. La segunda facultad hace referencia a la capacidad de comprender, acordar y aceptar principios compartidos de regulación social (Rawls, 2006, p. 140; 2002, p. 43).

Con esta descripción previa podemos señalar que los sujetos políticos son libres en tanto que se conciben a sí mismos, y unos a otros, como poseedores de la capacidad de tener y perseguir visiones particulares del bien y la vida buena. Libres en el sentido de que se conciben a sí mismos como facultados para exigir a sus instituciones aquello que promueva sus concepciones de bien en el marco de una concepción compartida de la justicia. Son iguales en el sentido de ser poseedores de facultades morales necesarias para intervenir en el desarrollo de la cooperación social. Esta presuposición antropológica rawlsiana permite extender las capacidades morales a todos los seres humanos, de forma tal que el universalismo moral se convierte en la base de su teoría política (Surotsev y Syrov, 2015, p. 177).

Tras presentar a los sujetos políticos como poseedores de facultades morales esenciales y como sujetos libres e iguales, Rawls señala que la pretensión de su teoría es establecer los principios de una sociedad bien ordenada (2002, p. 37). Esta sociedad exige cierto tipo de organización política donde todos los sujetos 
políticos reconocen y aceptan una misma e igual concepción política de justicia, tienen y comparten un sentido normalmente efectivo de esa concepción política de justicia y tienen, además, la convicción de que la estructura básica de la sociedad satisface los principios de justicia acordados libremente entre ellos. En una sociedad bien ordenada la concepción política de la justicia, que se desarrolla en la cultura política de una sociedad democrática, ofrece un punto de referencia político público sobre el cual rigen sus acciones las instituciones políticas y las relaciones entre los sujetos políticos.

Ahora bien, ¿cómo pueden los sujetos políticos llegar a un acuerdo sobre la concepción política de la justicia cuando cada uno persigue su propia concepción del bien? Rawls necesita diseñar un espacio abstracto de deliberación sobre los principios en el cual se puede llegar a un acuerdo de forma imparcial. La idea de la posición original es el presupuesto metodológico con el que se explica el núcleo del contrato social contemporáneo. Pero esta posición no puede entenderse desvinculada del velo de ignorancia, esto es, el presupuesto de que todos los que participan en la deliberación llegan allí desconociendo su lugar en el escenario político, social y económico. En la posición original con el velo de la ignorancia los deliberantes están en una situación de igualdad. Despojados de relaciones de fuerza e imposibilitados para que alguno pueda sacar un mayor provecho del resultado de la deliberación. Desconocen su posición social para evitar que sus intereses impidan trazar unos principios más universales y vinculantes. Los principios de la justicia que se erigen a partir de la posición original son dos:

1. Todas las personas son iguales en punto a exigir un esquema adecuado de derechos y libertades básicos iguales, esquema que es compatible con el mismo esquema para todos; y en ese esquema se garantiza su valor equitativo a las libertades políticas iguales, y solo a esas libertades.

2. Las desigualdades sociales y económicas tienen que satisfacer dos condiciones: primero, deben andar vinculadas a posiciones y cargos abiertos a todos en condiciones de igualdad equitativa de oportunidades; y segundo, deben 
Razón pública y justicia democrática: Los fundamientos teóricos de la democracia constitucional

promover el mayor beneficio para los miembros menos aventajados de la sociedad. (Rawls, 2003, p. 36)

Estos principios son consecuencia de la actividad de sujetos políticos libres e iguales que participan activamente en la construcción de lo público y ese ejercicio lo asumen como un bien propio. Estos principios cumplen un papel fundamental tanto en la materialización de las abstracciones conceptuales como en el desarrollo de la teoría política porque son el eje orientador de toda la práctica social y político-institucional. El desarrollo de la actividad política de gobernantes y gobernados se debe dar a la luz de estos principios y, en consecuencia, la legislación debe estar dirigida al desarrollo de estos principios. Por eso lo relevante que resulta el velo de ignorancia como restricción procedimental a las razones para acordar la concepción política de la justicia. Si las partes trazan los principios conforme a intereses particulares los principios no alcanzarán el grado de imparcialidad suficiente para que todos los asociados se sientan vinculados y tengan tales principios como ente rector de su comportamiento político. En este contexto, resulta llamativo que el marco procedimental rawlsiano permite a las partes buscar lo que es bueno para todos mientras persiguen su propio interés como individuos (Freeman, 2007; Floyd, 2017).

La presencia de los dos principios de justicia, con la primacía del primero sobre el segundo, que se erigen en la posición original y se desarrollan a lo largo de la legislación interna de sociedad como un sistema cerrado, unifica todos los conceptos anteriores. La cooperación y la participación de sujetos políticos iguales y libres, a partir de las facultades morales, está dirigida a permitir que a la luz de los principios de justicia se cree un orden jurídico justo y estable, donde cada asociado, según su concepción razonable de bien, pueda estar vinculado a ellos y de esa manera coexista unidad y diversidad. Esa fusión es lo que se busca con la idea del consenso entrecruzado ${ }^{3}$ como el acuerdo en torno los criterios compartidos de regulación de la cooperación social (Rawls, 2002, p.132). 


\section{EL LibERALISMo Político Y LA JUSTIFICACIÓN IUSFILOSÓficA DE LA CONSTITUCióN}

El liberalismo político en la historia es un acontecimiento eminentemente moderno. Generalmente se asocia su expansión con el final de la Segunda Guerra Mundial y la derrota del fascismo europeo, que puso fin -al menos en el ámbito teórico- a las pretensiones de imposición coercitiva de una sola concepción del bien y la vida buena:

El liberalismo político surge en la historia moderna como respuesta al interés por establecer unos medios en los que los individuos no tengan que renunciar a su fe y menos, que resuelvan sus conflictos religiosos a través de una confrontación bélica (Ammerman, 2010, p. 157). En torno al derecho de la tolerancia religiosa se concibe el origen del Estado moderno y, para construir una sociedad donde los ciudadanos libres e iguales puedan establecer reglas razonables de conducta política, aparecen los principios de justicia (Capella, 1997, p.135). Los hombres sostienen sus concepciones de bien en el interior de cada asociación a la que pertenecen. Así, los ciudadanos hacen uso de razones privadas en su vida ordinaria y se someten a estas reglas libremente. Con la misma libertad pueden prescindir de ellas. La razón pública cobija las discusiones políticas donde tienen cabida los asuntos más relevantes en torno a la vida en común y la cooperación social. En la medida en que las razones de las asociaciones y las razones del accionar político sean más coincidentes mayor será el orden de la sociedad, generando en este sentido un paradigma público y compartido de reflexión sobre los principios organizacionales de la sociedad (Hedrick, 2010, p. 187).

\footnotetext{
${ }^{3} \mathrm{El}$ consenso es entrecruzado porque permite reunir las prescripciones que una concepción compartida de la justicia impone con los intereses particulares de las partes deliberantes (Rawls, 2002, p. 140). Esto puede señalarse en relación con las pretensiones de los textos constitucionales contemporáneos que buscan establecer un marco político-jurídico de cooperación a través de derechos fundamentales que buscan promover el bien general, sin sacrificar los intereses particulares, en especial los intereses fundamentales de las minorías de toda índole (Chambers, 2019; Ferrajoli, 2014).
} 
Las reglas de las sociedades son consecuencia de cada forma particular de ver el mundo y de moverse en él. Sin embargo, hay un aspecto constitutivo del liberalismo político rawlsiano: no se reduce exclusivamente a las relaciones entre los ciudadanos con respecto al poder político en tanto que señala la necesidad de protección de los individuos dentro de las asociaciones a las que pertenecen. De tal manera, se busca garantizar que no haya discriminación en el orden interno, se vulnere la dignidad humana o se toleren relaciones desiguales entre hombres y mujeres. De la misma manera se establecen límites al Estado con respecto a las asociaciones. El liberalismo político, además de propender por un respeto a los derechos fundamentales y promover la igualdad de los ciudadanos, también otorga a las asociaciones la potestad de establecer reglas de juego. Al margen de la incumbencia del Estado. Es un límite de constante discusión. La libertad para crear reglas de juego y el límite del Estado para que dichas reglas no alteren el marco de la dignidad básica (Surovtsev y Syrov, 2015).

En consecuencia, el diseño que traza Rawls de una sociedad ordenada, democrática, plural y libre tiene un presupuesto básico: sujetar la acción de los sujetos políticos ${ }^{4}$ al texto constitucional (Botero, 2009, pp.152-158). La importancia del texto se sustenta en que allí están consagrados los derechos básicos que desarrollan los principios de igual libertad y diferencia (Restrepo, 2015). En la medida en que los asociados tracen su acción política conforme a la Constitución habrá mayores posibilidades de hacer posible la democracia. Este es sin lugar a dudas, uno de los mayores legados de la teoría rawlsiana: la justificación iusfilosófica de la Constitución como garante de los intereses de los sujetos políticos. Este aspecto determina precisamente el paradigma contemporáneo de la democracia constitucional en tanto que genera exigencias sustanciales de legitimación de las acciones políticas y no depende solamente de los procedimientos electorales regidos por la regla de la mayoría (Ferrajoli, 2008; 2014). Es por eso que se

\footnotetext{
${ }^{4}$ Por sujetos políticos entendemos todos los posibles actores sociales que interactúan en los múltiples entramados sociopolíticos. Desde actores individuales como ciudadanos particulares hasta actores colectivos como partidos políticos o empresas caben en esta denominación (Benz, 2010, pp. 237-238; Kreide, 2007).
} 
requiere de una institución que asegure la coherencia entre la acción jurídica y la Constitución. Como consecuencia del modelo norteamericano, del cual bebe Rawls, este órgano será el Tribunal Constitucional.

La sujeción de la acción política al texto constitucional garantiza la dirección de los actores políticos de forma tal que sus acciones públicas sean coherentes con los principios establecidos para la concepción política de la justicia. Así, los ciudadanos son la base de la legitimidad constitucional, lo que hace el Tribunal es garantizar que efectivamente el acceso por la reivindicación de los derechos básicos no sea un acto exclusivo de las mayorías, las cuales fácilmente pueden dirigir, en favor suyo, el curso de las decisiones políticas. En nombre de la defensa de la Constitución, el Tribunal, debe intervenir de forma tal que la dignidad moral presupuesta en la consolidación de los principios de justicia no sea vulnerada en el juego político. De tal manera que cuando el legislador omite, por conveniencia o miopía política, asignarles a los grupos minoritariamente excluidos el acceso a las garantías de las esencias constitucionales y los asuntos de justicia básica, resulta legítima y necesaria la intervención del Tribunal.

El eje de acción del Tribunal Constitucional no es el oportunismo electoral sino el efectivo reconocimiento de los derechos básicos para todos (Ferrajoli, 2014, p 56; Mandle, 2009, p. 83). La forma en que toda acción política, en cuanto toque los derechos básicos, esté sujeta al texto constitucional, es lo que Rawls denomina razón pública: "facultad y modo en que una sociedad política traza sus planes, fija sus fines en un orden de prioridades y toma decisiones de acuerdo con ese orden" (2003, p. 245). Esta facultad y modo de proceder cabe exclusivamente en un régimen democrático porque la razón pública es la razón de sus ciudadanos. Y en tanto que el Tribunal Constitucional garantiza la coherencia entre la Constitución y la ley, éste es su máxima expresión. En regímenes diferentes a la democracia, la reflexión sobre el bien social está condicionada por los intereses de quienes conservan una posición de dominación (Zambrano, 2001, p. 874). 
Los límites impuestos por la razón pública no rigen para todas las cuestiones políticas sino solo para aquellas que implican esencias constitucionales y asuntos de justicia básica. Los límites de la razón pública no rigen en nuestras concepciones particulares del bien. Sí rigen, en cambio, a los ciudadanos en el modo de votar cuando las esencias constitucionales y los asuntos de justicia básica están en juego. Cuando éstos se asocian en partidos políticos y debaten acerca de políticas públicas. Rigen a legisladores cuando están en el hemiciclo parlamentario. Y rigen de una manera muy especial al Tribunal Constitucional en el ejercicio del control constitucional (Tobón \& Mendieta, 2018). Esta función asignada en una democracia constitucional al Tribunal Constitucional, y su efectivo ejercicio, es la manifestación institucional de la razón pública como consenso entrecruzado entre una pluralidad de concepciones del bien. Ni los legisladores ni el ejecutivo deben justificarse tan rigurosamente como debe hacerlo el Tribunal Constitucional. Rawls desarrolla la idea de razón pública discutiendo los siguientes aspectos: cómo esta se relaciona y depende de la idea de ciudadanía democrática; cuáles son las diferencias entre razones no públicas y públicas; cuál es el contenido de la razón pública; qué son esencias constitucionales y asuntos de justicia básica; por qué el Tribunal es el paradigma de la idea de razón pública.

\section{Cómo la razón pública se relaciona y depende de la idea de ciudadanía} democrática

¿Por qué en el momento de discutir las cuestiones políticas más fundamentales los asociados deben acudir a los límites de la razón pública y no a sus concepciones de bien? Responder esta pregunta exige tener como visor lo que Rawls define como principio de legitimación liberal, el cual señala que la validez del ejercicio del poder político que los ciudadanos ejercen mediante el voto se expresa en la Constitución, escenario en el que se consagran esencias que pueden razonablemente presumirse como vinculantes para todos. Una concepción no democrática de razón pública reduce los límites de acción solo a funcionarios públicos que administran el poder político, dejando por fuera de los límites de la razón pública la acción política de los 
ciudadanos. Una concepción democrática de la idea de razón pública, para Rawls, tiene la peculiaridad de vincular y regir mediante sus límites todas las discusiones políticamente esenciales de los particulares. Es de esperar que a través de la sujeción de los funcionarios públicos a la razón pública se establezcan parámetros interpretativos que orienten la acción política de los ciudadanos.

Los límites de la razón pública y la idea de ciudadanía democrática se conectan armónicamente mediante la presencia del principio de legitimación liberal porque se entiende que los ciudadanos, dentro de la estructura básica de la sociedad, en la que han nacido y en la que han de desarrollar un ciclo vital completo, ostentan una igual porción de poder político, coercitivo y público, con el que se regulan unos a otros. Este fundamento razonable de las acciones políticas, sin desconocer las diferentes concepciones de bien, explica el ideal de ciudanía democrática. Cuando los ciudadanos versan su discusión en asuntos que atañen a las esencias constitucionales o los asuntos de justicia básica, su argumentación y acción políticas, regidas por los límites de la razón pública establecen la exigencia razonable del reconocimiento.

Frente a cuestiones políticas fundamentales la idea de razón pública rechaza el hecho de que los electores plasmen sus preferencias según sus intereses individuales porque ello conduciría a pensar la democracia como una regla de mayorías. La idea de razón pública, aunque reconoce que en la acción política no se le puede poner límites fácticos al poder mayoritario, sí establece como criterio rector que las esencias constitucionales no sean alteradas por una coyuntura pasajera o una mayoría malintencionada. El Tribunal Constitucional está llamado a ser el filtro, limitado por la razón pública que se expresa en los principios y valores de la Constitución, que impida la fácil atomización de los derechos fundamentales.

\section{Diferencias entre razones no públicas y públicas}

Existen muchas razones no públicas pero una sola pública. Las razones privadas no son aquí objeto de discusión. Razones no públicas son aquellas que 
rigen y orientan las decisiones y directrices de las asociaciones que conforman el conglomerado social como iglesias, familias, instituciones educativas o recreativas y que, en suma, representan las concepciones razonables de la vida buena de los sujetos políticos. Son razones públicas en su condición de asociados a las respectivas instituciones con las cuales cada sujeto comparte y profesa una particular visión del mundo y la realidad, pero no son públicas con respecto de la sociedad política y de los ciudadanos en general. Los ciudadanos están revestidos de derechos básicos para asociarse y retirarse de dichas asociaciones, sin que ello implique una sanción legal.

La razón pública es una sola, vinculante, coactiva y obligatoria como producto del consenso entrecruzado entre los sujetos políticos. Se espera que como consecuencia de un pensamiento reflexivo y de un juicio razonado, se acepten libremente los ideales, principios y pautas que definen los derechos y libertades básicos, con los cuales se rige el poder político con el que se sujeta a la totalidad de los ciudadanos. Es incorrecto decir que el liberalismo se concentra solo en los derechos de los individuos; más bien, los derechos que reconoce sirven para proteger asociaciones, grupos más pequeños e individuos unos respecto de otros en un balance apropiado determinado por sus principios orientativos de justicia (Rawls, 2003, p. 256).

\section{Contenido de la razón pública}

La razón pública consiste en el consenso entrecruzado logrado entre los sujetos políticos sobre los principios de justicia. Dicha concepción política de la justicia hace referencia, en primer lugar, a una lista de derechos, libertades y oportunidades básicos; en segundo lugar, busca otorgar prioridad a esos derechos, libertades y oportunidades básicos; además, pretende establecer medidas que aseguren a los ciudadanos el ejercicio efectivo de esos derechos, libertades y oportunidades básicos determinados por los principios de justicia. 
En la medida en que los dos principios de justicia están estrechamente relacionados con la concepción política de la justicia, dicha concepción implica: (i) que se aplique en la estructura básica de la sociedad como un esquema unificado de cooperación social; (ii) que se presente de manera independiente a cualquier doctrina comprehensiva y, (iii) que esté elaborada en términos de ideas políticas fundamentales incluidas en la cultura política democrática. En este sentido, una concepción política de la justicia debe tener unos principios de justicia y orientaciones de indagación, que definan modos de razonar y criterios para evaluar si los postulados de esta concepción política se aplican efectivamente (Mandle, 2009; Kukathas y Pettit, 1990). De la mano de las orientaciones de indagación debe incluirse una lista de virtudes públicas tales como la razonabilidad y la disposición a respetar el deber moral de la civilidad.

Identificar la concepción de justicia más razonable es resultado de un ejercicio deliberativo. Si se impone, como consecuencia del poder que políticamente ejercen unos sobre otros, se desmiente la pretensión democrática de la idea de razón pública. Los asociados se someten a un periodo en el tiempo de competencia ordenada que permita identificar los argumentos más razonables. Consolidar consensualmente la concepción política de la justicia es una cuestión crucial porque allí están contenidos los asuntos de justicia básica y las esencias constitucionales.

\section{Esencias Constitucionales y asuntos de justicia básica}

La razón pública rige las acciones políticas de las instituciones y de los asociados en aquellos casos en que estén en juego las esencias constitucionales o los asuntos de justicia básica. En lo concerniente a las esencias constitucionales, Rawls realiza una distinción entre los dos principios de justicia que se trazan desde la posición original. El primer principio señala una igualdad de derechos y libertades básicos. El segundo principio regula asuntos básicos de la justicia distributiva tales como igualdad de oportunidades; desigualdades sociales y económicas; así como las bases sociales del autorrespeto. De este modo, en

\section{DERECHO GLOBAL. ESTUDIOS SOBRE DERECHO Y JUSTICIA}


una sociedad democrática con un Tribunal Constitucional que ejerce control jurisdiccional sobre la actividad legislativa, le será competencia básica conocer de asuntos que versan sobre derechos y libertades básicas bajo el marco de esencias constitucionales; y de asuntos atinentes a la desigualdad de oportunidades y económicas bajo el marco de los asuntos de justicia básica.

\section{El ORdeN JURÍdico A LA LUZ de LA RAZÓN PÚBLICA}

La relación entre razón pública y el Tribunal Constitucional se sustenta en dos premisas. En primer lugar, la razón pública es la razón del Tribunal Constitucional cuando este se desempeña como supremo intérprete de la Constitución; en segundo lugar, el Tribunal Constitucional es la rama del poder público que sirve como modelo de la razón pública. Esto implica a su vez cinco principios funcionales dentro de la constitucionalidad de las decisiones en el marco de la razón pública: (i) Distinción entre poder constituyente del pueblo y poder ordinario de los funcionarios públicos (p. 266); (ii) Distinción entre Constitución y ley ordinaria; (iii) Concepción de la Constitución democrática como expresión de principios políticos; (iv) Todo texto constitucional democrático debe permitir que sea el cuerpo de ciudadanos quien establezca decididamente determinadas esencias constitucionales tales como igualdad de derechos y libertades básicos; libertad de expresión y de asociación; derechos y libertades que garanticen seguridad e independencia ciudadana y, (v) Poder del Pueblo como poder superior y equilibrio entre las ramas del poder público (p. 268).

El establecimiento de los cinco principios del derecho constitucional en el interior de una democracia constitucional permite señalar la importancia de la distinción entre poder constituyente y poder ordinario, de la distinción entre la ley suprema del pueblo y la ley ordinaria que establece el cuerpo legislativo, la primacía del poder constituyente sobre el poder legislativo, la imposibilidad de establecer límites al poder constituyente primario y la inadmisión de la supremacía ilimitada del Parlamento (Gargarella, 2005). 
En las dinámicas políticas propias de los sistemas contemporáneos, puede ocurrir que mayorías parlamentarias en ejercicio de la función legislativa, ajusten las leyes ordinarias conforme a intereses particulares no razonables (Chambers, 2019; Ferrajoli, 2014). El ejercicio de la revisión judicial que ejerce el Tribunal Constitucional, como representante del pueblo y garante de sus intereses plasmados en la Constitución, le permite confrontar el contenido de dicha ley ordinaria mayoritaria con los principios de justicia que irradian el texto constitucional. En este sentido, la razón pública impone límites a la capacidad de decisión de las instituciones democráticas en tanto que estas deben respetar una serie de criterios normativos definidos a través del consenso entrecruzado. De la confrontación entre la Constitución y la ley ordinaria mayoritaria puede encontrar el TC que existe una contradicción entre una y otra. De tal manera que, atendiendo al principio de la supremacía de la ley del pueblo sobre la ley ordinaria, el TC tiene la potestad de impedir que tal norma ingrese al orden jurídico sin que ello lesione el espíritu democrático o anule la carga legítima de la actuación del Tribunal Constitucional. El Tribual Constitucional actúa en nombre del pueblo y en defensa de la Constitución. Al asegurar la defensa de los preceptos que estructuran la Constitución del devenir político, encarna la expresión de la razón público del deterioro que puede causar el poder mayoritario a la misma democracia (Beaud, 2017, p. 10).

El punto de partida de la teoría rawlsiana consiste en determinar las condiciones mínimas de una sociedad justa y estable, con instituciones sociales que garanticen la promoción y la defensa de los dos principios de justicia. La justicia es un supuesto que no admite transacciones dado que figura como la primera virtud de las instituciones sociales y no necesita de las mayorías para su justificación. Por esta razón, la discusión de Rawls con la tradición utilitarista consiste en entender la justicia como una virtud que no está sujeta al beneficio de algunos; así estos representen a los grupos mayoritarios (Scheffler, 2005). 
De aquí se sigue la importancia de la abstracción metodológica que representa la posición original con el velo de la ignorancia, pues este momento "hace posible un consenso unánime con garantías procedimentales suficientes para asegurar el contenido universal, autónomo y consensual de los principios de justicia seleccionados." (Mejía, 2005, p. 106). El velo de ignorancia obliga a negociar bajo la perspectiva del universalismo moral, esto es, el supuesto bajo el cual se determina que los asociados que participan en la deliberación desconocen su posición social, sus talentos, sus capacidades y las condiciones económicas y políticas de la sociedad (Rawls, 2006, p. 120; 2002, pp. 120-121).

Dado que hay ausencia de información sobre asuntos sociales y económicos, el criterio por el cual resulta confiable que agentes desinformados lleguen a determinar los dos principios de justicia es por cuanto éstos están dotados de unos bienes sociales primarios, fundamentales para el individuo en tanto ciudadano y sujeto moral. Estos bienes sociales primarios hacen referencia a las libertades básicas (pensamiento, conciencia, asociación); bases sociales de auto-respeto; libertad de movimiento y de ocupación. Los bienes sociales primarios son requisitos necesarios para desarrollar un plan de vida racional y razonable. "Los bienes sociales primarios constituyen, a su vez, la columna vertebral de lo que Rawls ha denominado su concepción kantiana de la justicia como imparcialidad" (Mejía Quintana, 2005, p. 111).

El acto legítimo deliberante, participativo e inclusivo de construcción de los dos principios de justicia, les confiere la facultad de desempeñar el papel de agentes reguladores de la estructura básica de la sociedad. Es así entonces como resulta posible afirmar que los principios son: (i) fundamento dialógico-moral extrasistemático del orden jurídico positivo; (ii) criterio de legitimidad e interpretación de todas las medidas que el Estado tome en torno a la sociedad; (iii) fundamento que orienta el comportamiento público-político tanto de las instituciones como de los particulares; (iv) criterio orientador del desarrollo constitucional y normativo 
de la sociedad y, (v) criterio legitimador del modelo político en tanto dé cuenta de un procedimiento inclusivo, abstracto y universal.

Una vez han sido fijados los dos principios de justicia, que atienden las pretensiones de igualdad y libertad es de esperarse jurídicamente que éstos irradien todo el ordenamiento jurídico. Los dos principios pasan a orientar el contenido normativo (Floyd, 2017). Lo que resulta posible definir en una lectura jurídica es que sea la normativa interna (Constitución y leyes) el conjunto de disposiciones normativas que desarrollan los dos principios de justicia. Al decir desarrollo, se quiere indicar que el orden jurídico materializa a través de reglas y principios la forma en que se hace legible la libertad, la igualdad y la diferencia. El orden jurídico inicia con la orientación de los dos principios. La Constitución consagra los derechos fundamentales que le dan sustrato material a la dignidad, a la supervivencia o la autodeterminación (Restrepo, 2018, 57). En este sentido, la protección de estos derechos es función de todo el conglomerado social; pero de una forma muy especial del Tribunal Constitucional. La salvaguarda de estos derechos frente al actuar público de los sujetos y las instituciones es una confirmación de la protección de los dos principios.

El orden jurídico positivo de una sociedad bien ordenada, se gesta desde los dos principios de justicia, que deben asegurar una participación imparcial y abstracta (Rawls, 2002, p. 73). La justicia institucional radica en que efectivamente las instituciones actúen de tal forma que resulte legible el desarrollo de tales principios. En caso de no hacerlo, los asociados están facultados para acceder a la desobediencia civil (Rawls, 2006, p. 306). La civilidad es un requisito básico para mantener la estabilidad socio-política. En caso de desconocer los principios, las instituciones no gozan de autoridad moral para imponer obediencia. La mejor forma en que se evidencia la procedencia de las instituciones conforme a los dos principios tiene que ver con la promoción de la participación y la veeduría ciudadana. Es necesario que las instituciones faciliten la realización individual 
de los ciudadanos. Y que estos a su vez se apoyen entre sí. "El deber natural más importante es el de apoyar y fomentar las instituciones justas." (Rawls, 2006, p. 306).

El orden jurídico es dinámico. Toda sociedad liberal se reserva el derecho de revisar sus disposiciones normativas. Es una función básica de las instituciones hacerlo y permitir que los sujetos políticos también lo hagan. Es por eso que el orden jurídico en el que se materializan los dos principios de justicia, surge y se asienta en un régimen democrático constitucional. La sociedad política en conjunto es receptora y promotora de las disposiciones normativas. La facultad de disenso, propia de los regímenes democráticos es un derecho en el que la desobediencia en tanto acto público, político y no violento permite que grupos políticos minoritarios exijan de las mayorías la revisión y reforma de una norma en la que han resultado desconocidos sus derechos básicos. Cuando la libertad y la igualdad se desconocen sistemáticamente dentro del orden jurídico, existe la facultad moral de hacer un llamado público. El foro público debe permanecer abierto para que se discutan los asuntos problemáticos cruciales de la sociedad política bien ordenada. El Tribunal Constitucional debe garantizar la participación inclusiva y los dos principios de justicia habrán de ser el fundamento básico de la construcción jurídica y política.

\section{Conclusiones}

La mejor manera de comprender la propuesta de John Rawls exige necesariamente adentrarse en su concepción de mundo conforme a las pistas que él mismo establece en la primera parte de todos sus textos. Algunas de esas pistas son: posición original; velo de ignorancia; sociedad bien ordenada; bienes sociales primarios; dos principios de justicia; razón pública; consenso entrecruzado; pluralismo razonable; equilibrio reflexivo; ciudadanos como personas libres e iguales. A lo largo de su producción bibliográfica es posible identificar modificaciones en la interpretación y lugar que ocupan dichas pistas 
en el conjunto de su teoría. Pero todas ellas cumplen una función esencial: servir de base en el desarrollo de la adaptación de una idea de justicia que permita la cooperación y la convivencia de todos los asociados de una forma democrática, plural y estable.

Rawls se ubica en la orilla del liberalismo y la democracia. Rechaza el utilitarismo y no acepta la consigna de que la ley de los más es buena o moralmente justificable en sí misma. Se aparta del intuicionismo porque, a su juicio, el orden de los principios está condicionado. El llamado orden lexicográfico hace referencia a la estricta sujeción de atención entre un principio y otro. Solo procede la atención del segundo cuando el primero haya quedado satisfecho. Su conexión moralpolítica lo hace intransigente con la distribución parcial de los recursos. Acepta la desigualdad, como condición genradora de beneficios para los menos aventajados. Por eso es clave pensar que toda su obra está delimitada por el establecimiento y la defensa de los dos principios de justicia.

Todas las instituciones sociales están llamadas a actuar de conformidad con el desarrollo de dichos principios. Si es legible que actúan con sujeción a ellos, los sujetos públicos, que son razonables, comprenderán que tales instituciones les merecen toda la obediencia. Hay una relación de reciprocidad entre mando y orden y la matriz es la sujeción a los dos principios. Cada sujeto político también está llamado a aceptar tales principios. Y no como consecuencia de una imposición del régimen político puesto que allí mismo se desvirtuaría cualquier pretensión democrática. El modelo social que Rawls concibe está dado para que todos los asociados encuentren que existe una correlación entre su concepción razonable de bien y el contenido de los dos principios de justicia. Tales principios son un marco general y abstracto, que permite la inclusión de múltiples concepciones razonables de bien. Así que nadie tiene que renunciar a su concepción razonable de bien. Los asociados están llamados a aceptar que todos los demás vivan conforme a sus ideas de bien, así sean disímiles unas y otras. El punto de encuentro son los dos principios de justicia, criterio legitimador básico de todo el orden social. 
Cada sociedad política liberal desarrolla los dos principios de justicia, que son generales y abstractos, conforme a unos derechos básicos que aparecen consagrados en el texto constitucional. Tal texto es el punto de referencia para la sociedad política. Allí se consagran las principales reglas del juego jurídico-político. Se establecen los límites y se determinan las concesiones más razonables para que los sujetos interactúen desde el punto de vista del poder. La extensión de los dos principios de justicia al orden jurídico constitucional determina el establecimiento de una institución que en el mundo moderno parecía no tener cabida. En el marco moderno del desarrollo de la democracia liberal, el Parlamento era el amo y señor de la dirección política.

En el mundo contemporáneo, el Tribunal Constitucional, está llamado a garantizar que esos derechos básicos, en tanto son concreción de los dos principios, sean efectivamente respetados. Que no haya facultades políticas para que las mayorías dirijan el contenido constitucional conforme a sus intereses. El Tribunal Constitucional está en el medio del derecho y la política, por eso su actuación resulta problemática. Para algunos incluso, ilegítima. Sin embargo, no es un ente ilimitado. También lo condiciona el respeto por los derechos básicos. Y toda sociedad que a través de sus derechos básicos le da cuerpo a los dos principios de justicia, se asegura un mayor respeto por la diferencia, la tolerancia y la pluralidad. De tal manera que el ideario liberal sea más que una consigna. Que su espacio fecundo sea una realidad entre los agentes políticos que no solo quieren vivir más sino mejor.

Así, la teoría de Rawls nos permite identificar los valores propios de una democracia constitucional en tanto que establece los criterios normativos de restricción al tipo de decisiones que pueden ser tomadas en los contextos democráticos. Las pretensiones de fundamentar la legitimidad política en la aclamación popular, pueden ser discutidas desde la perspectiva deliberativa de la justicia como imparcialidad y la idea de razón pública. 
El vínculo interno entre democracia, razón pública y Constitución establecido por Rawls, nos muestra que no puede haber democracia sin derechos ni garantías de esos derechos y, frente a las corrientes políticas actuales de autoritarismo populista, la idea de los límites constitucionales a la aclamación mayoritaria encuentra su sustento teórico en la posición político-filosófica del pensador norteamericano. 


\section{Bibliografía}

Alútiz, J; “Homenaje póstumo a John Rawls". Isegoría. 2004, No 31. Pp. $1-41$.

Ammerman, N; (2010). "The Challenges of Pluralism: Locating Religion in a World of Diversity." Social Compass, vol. 57(2), pp. 154-167.

Beaud, O; Los últimos días de Weimar: Carl Schmitt ante el ascenso del nazismo. 2017. Madrid: Escolar y Mayo.

Benz, A; El Estado moderno. Fundamentos de su análisis politológico. 2010, Madrid, Centro de Estudios Políticos y Constitucionales.

Botero, A; La tolerancia en la historia. Medellín, 2009, Sello editorial Universidad de Medellín.

Capella, J; Fruta prohibida: una aproximación histórico teorética al estudio del derecho y del estado. 1997, Madrid, Trotta.

Chambers, S; "Democracy and Constitutional Reform: Deliberative versus Populist Constitutionalism" Philosophy and Social Criticism, 2019, Vol. 45(9-10), pp. 1116-1131.

Ferrajoli, L; Democracia y garantismo. 2008, Madrid, Trotta.

Ferrajoli, L; La democracia a través de los derechos. El constitucionalismo garantista como modelo teórico y proyecto politico. 2014, Madird, Trotta.

Floyd, J; "Rawls' methodological blueprint", European Journal of Political Theory, 2017, Vol. 16 (3), pp. 367-381.

Fraguas, L; "El concepto de derechos fundamentales y las generaciones de derechos." Anuario del centro de la UNED de Calatayud. 2015, No 21, pp. 117-136.

Freeman, S; Rawls. 2007, New York: Routdledge.

Gargarella, R; "El constitucionalismo según John Rawls" Araucaria. 2005, Vol 7, No 14.

González Vicén, F.; El Positivismo en la Filosofía del Derecho contemporánea, Madrid, Instituto de Estudios Políticos, 1950, 96 pp. 
González Vicén, F.; "La Filosofía del Derecho como concepto histórico", Anuario de Filosofía del Derecho, XIV, 1969, pp. 1565.

Hedrick, T; "Coping with constitutional indeterminacy John Rawls and Jürgen Habermas" Philosophy \& Social Criticism, 2010, Vol. 36, No. 2, pp. 183-208.

Kreide, R; "Justicia global, Derechos Humanos y responsabilidad ¿tienen obligaciones las empresas multinacionales?” En: Giusti, M. y Cortés, F. (eds.), Justicia Global, Derechos Humanos y Responsabilidad, 2007, Bogotá: Siglo del Hombre Editores, pp.101-134.

Kukathas, Ch. y PETTIT, P; Rawls. A Theory of Justice and its Critics. 1990, California, Stanford University Press.

Levitsky, S. y ZIBLATT, D; Cómo mueren las democracias. 2018, Barcelona, Ariel.

Mandle, J; Rawls's A theory of justice. An Introduction, 2009, Cambridge, Cambridge University Press.

Mejía, O; Teoría política, democracia radical y filosofía del derecho. 2005, Bogotá, Temis.

Mounk, Y; El pueblo contra la democracia. Por qué nuestra libertad está en peligro y cómo salvarla. 2018, Barcelona, Paidós.

Pogge, T; "John Rawls, una biografía”. Coherencia. 2010, Vol. 7, No. 12, pp. 13-42

Rawls, J; Justicia como equidad: una reformulación. 2002, Barcelona: Paidós

Rawls, J; Liberalismo Político, 2003, Barcelona: Crítica.

Rawls, J; Teoría de la Justicia, 2006, México, FCE.

Restrepo, J; Estructura constitucional del estado colombiano. 2018, Medellín, Sello editorial Universidad de Medellín.

Restrepo, J; "Aproximación al pensamiento jurídico-político de Hans Kelsen" Revista Jurídicas, 2015, Vol. 12, ํ1, pp. 43-58.

Scheffler, S; “Rawls y el utilitarismo”. Araucaria. 2005, Año 8. No 14. 
Surovtsev, V. y Syrov, V; “Outlooks of J. Rawls's theory of justice”, Procedia - Social and Behavioral Sciences. 2015, No. 166, pp. 176 $-181$.

Tobón, M y Mendieta, D; "El (des)control constitucional en Colombia" Estudios constitucionales. 2018, Vol 16, pp. 51-88.

Van Parjis, P; "La doble originalidad de Rawls" Cuadernos de economía. 1994, Vol 14, No 21, pp 7 - 33.

Wenar, L; “The Unity of Rawls's Work". Brooks, T. y Freyenhagen, F (eds.). The Legacy of John Rawls. 2005, New York: Continuum, pp. 22-33.

Zambrano, P; "La razón pública en Rawls". Anuario da Facultade de Dereito da Universdade da Coruña. 2001, No 5, pp. 871 - 886. 


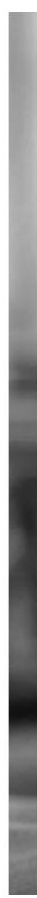

